in a series of 32 samples of cerebrospinal fluid in which xanthochromia was found on spectrophotometry. ${ }^{2}$ Failure to see xanthochromia does not exclude subarachnoid haemorrhage.

Secondly, only eight patients had an entirely normal computed tomogram. This rate of false negative results $(3.8 \%(8 / 208))$ is rather low since the sensitivity of computed tomography is only $95 \%$ on the day of bleeding and falls thereafter. ${ }^{3}$ In addition, the patients in whom the computed tomogram was normal were significantly more likely to have xanthochromia than those in whom it showed an abnormality $(6 / 8 v 6 / 18, \mathrm{P}<0.05)$. This finding, which at first may seem paradoxical, is consistent with the hypothesis that the group with no abnormality on computed tomography is depleted by the misdiagnosis and exclusion of those without xanthochromia. Clearly, those with an abnormality on computed tomography are not subject to this potential source of misdiagnosis.

It has been stated that bloodstained cerebrospinal fluid without xanthochromia when the computed tomogram is normal can be explained by thunderclap headache and a traumatic lumbar puncture. ${ }^{4}$ In view of our findings we suggest that this could cause subarachnoid haemorrhage to be overlooked, particularly if the cerebrospinal fluid sample is taken within 12 hours of the onset of symptoms or if the supernatant is assessed by visual inspection: in both these cases xanthochromia may be absent in patients with subarachnoid haemorrhage. We believe that if the clinical suspicion of subarachnoid haemorrhage is sufficient to merit computed tomography then a lumbar puncture is indicated if the computed tomogram is normal. Uniform bloodstaining of the cerebrospinal fluid is highly suggestive even in the absence of xanthochromia and merits either conventional angiography or magnetic resonance angiography. This approach should prevent subarachnoid haemorrhage arising from an intracranial aneurysm going unrecognised.

FRRGUS COAKLEY

Senior registrar in radiology NICK MESSIOS

Consultant neuroradiologist Leicester Royal Infirmary,

Leicester LE1 5WW

1 Sakas DE, Dias LS, Beale D. Subarachnoid haemorrhage presenting as head injury. BMY 1995;310:1186-7. (6 May.)

2 Soderstrom CE. Diagnostic significance of CSF spectrophotometry and computed tomography in cerebrovascular disease. tometry and computed tomography in cerebrovascular

3 Vermeulen M, Van Gijn J. The diagnosis of subarachnoid haemorrhage. I Neurol, Neurosurg Pyychiatry 1990;53:365-72.

4 Rinkel GJE, Wijdicks EFM, Hasan D, Kienstra GE, Franke CL, Hageman LM, et al. Outcome of patients with subarachnoid haemorrhage and negative angiography according to pattern of haemorrhage on computed tomography. Lancet 1991;338: 964-8.

\section{Medicine and nursing}

\section{Medicine and nursing need both scientific and naturalistic inquiry}

EDITOR,-The issue of the $B M 7$ of $29 \mathrm{July}$, exploring how nursing and medicine may interact more usefully, should prompt the nursing journals to initiate a similar debate in their pages. It was with dismay, though, that we read the two letters ${ }^{12}$ concerning an article by Hay. ${ }^{3}$ Although Hay's article received comment in the nursing press, the arguments surrounding it provide a timely rejoinder to the articles in the $B M \mathcal{F}$. The enthusiasm and impatience of nurses and midwives to develop research based practice, albeit within a framework that encompasses more than the scientific paradigm, is obvious to those in the professions. A recent series of workshops throughout Britain on the use of research in nursing led by one of us has reinforced this impression.

Hay is labouring under the misconception that "bedside nursing" is solely an intuitive activity synonymous with the caring role of wife or mother and therefore in no need of a research base. Nothing could be further from the truth. Both objective science and more naturalistic methods of inquiry have a part to play, the former answering such questions as "Which is the most effective pressure relieving mattress?" and "Which urethral catheter is least likely to become blocked or infected?" and the latter addressing different issues, such as whether a hospital waiting list is really a queue and what in reality happens during the interactions between nurses and their clients. Indeed, nursing and midwifery have been far more progressive than medicine in recognising that health care research, involving as it does the social world of carers and patients, cannot be tackled solely through the scientific model-as witnessed by the fact that the $B M \mathcal{Y}$ has only recently published a series of articles outlining the scope and application of methods in qualitative research. ${ }^{4}$ It is not just science and mathematics (as Hay implies) in which health care researchers need to be proficient.

We agree that not all practitioners, be they doctors or nurses, should be expected to undertake research. If research based practice is to become a reality, however, then practitioners must be able to critically appraise both original research articles and reviews. To suggest that nursing or nurse should not strive to meet these standards does a disservice both to the profession and, more importantly, to those for whom it provides care.

ANNE MULHALI

Woking, Independent training and research consultant

Surrey GU22 OPT

ANNE JONES

Department of Nursing, Research assistan

King's College,

London

1 Barton M. A nurse's place is at the bedside. BMf 1995;311:325. (29 July.)

2 Hay RL A nurse's place is at the bedside. BMF 1995:311:325. (29 July.)

3 Hay R. A num

$$
\text { 1994;8:42-3. }
$$

. Reaching the parther methods cannot reach: an introduction to qualitative methods and health services research. BMY 1995;311:42-5. (1 July.)

\section{Nurses should have experience of medical} training

EDITOR,-I agree with Jane Salvage that the traditional division of labour between doctors and nurses is changing and that nursing work is currently undervalued.' The move towards the ideal of expert nurses complementing but not substituting for expert doctors to provide a better service for patients must be based on mutua understanding of each other's current roles. Many doctors are ignorant of nursing work. I believe however, that nurses are equally if not more ignorant of doctors' work. Most medical courses address doctors' ignorance of nursing work to some extent by incorporating some experience in nursing work. As far as I am aware, the converse is not true. Perhaps this should be considered in nursing courses to help mutual understanding.

NEIL SIMPSON

Child Health Department, Senior registrar in child health Bath Wert Community NHS Trust Bath BA1 3QE

1 Salvage J. What's happening to nursing? BMF 1995;311:274-5 (29 July.)

\section{Senior nurses are out of touch}

EDITOR,-Jane Salvage's attempts to examine what is happening to nursing is notable for its rejection of

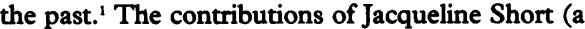
nurse who became a doctor) and Ann Bradshaw (a lecturer in nursing), both with a different view, ${ }^{2}$ are said to show shaky reasoning and nostalgia for a mythical golden age.' M Barton ${ }^{3}$ rejects Hay's assertion" that the nursing leadership is "frogmarching" nursing towards clinical autonomy (and research) against the wishes of the "rank and file." Our experience is that this is the case-not for every nurse, and clearly not for Barton, but for many. Acceptance of autonomy seems to be limited by an accountability that is equated with fear. This is engendered by a disciplinary regime often implemented by those who shout loudest on professionalism and relations with medicine.

Unlike the medical hierarchy, leaders in nursing rarely care for patients routinely in the same context as the rank and file. Many experienced ward nurses find themselves alienated from the leaders' views, often feeling unable to dissent in public or in print.

The public has its own clear idea of what nurses do. Booth has characterised nursing in terms of both mechanical and very complex functions, exemplified by plumping pillows and comforting patients. ${ }^{5}$ Many fear that leaders in nursing with a rather different agenda are hijacking their profession. Evolution is inevitable and necessary, but if the future holds a new role so radically different that those who are currently known as nurses may not be willing or able to accept it, then those who devise the successful model should find a distinctive name for their new profession. The future of nursing cannot exclude nurses, leaving the "basics to the untrained while we go ever higher."

Whether nurses should accept further mechanical responsibilities that are rightly no longer considered to be appropriate for junior doctors is a matter for debate. Currently, nurses who have been so trained at times refuse to exercise these skills, invoking their professional autonomy when they are not happy about inadequate time being left for their more traditional work. A radical approach to "structural inequalities of sex and hierarchy"' is not the answer, especially as entry to medicine at least is now independent of sex. Leaders in nursing may have lost their way in sociological theories, whose popular face has become an obsession with "handmaidenism," but the real problem lies elsewhere. The rank and file have seen the future, and it is understaffed.

EILEEN CUMMINS JEREMY S STERN Nelson Hospital,

London SW20 8DB

1 Salve S. What's happening to nursing? $B M$ f 1995;311:274-5. (29 July.)

2 Short JA, Bradshaw A, Nolan $M$, Lempp $H$. Has nursing lost its way? $B M F$ 1995;311:303-8. (29 July.)

3 Barton M. A nurse's place is at the bedside. BMY 1995;311:325. (29 July.)

4 Hay R. A nurse's place is at the bedside. Nursing Standand 1994;8:42-3.

5 Booth B. Conduct unbecoming. Nursing Times 1995;91:56.

\section{Problems of hierarchy are not confined to nursing}

EDITOR, - The correspondence between M Barton and Robert L Hay ${ }^{2}$ clearly illustrates the difficulties that doctors and nurses have when trying to understand one another's changing professions. Both professions will continue to face profound changes in the way they practise. Change is always difficult and provides a rich environment for discontent and suspicion. It is only by trying to understand the pressures on each other's professions that we can avoid destructive bickering and conflict, which would weaken the public's confidence in our professionalism. Two articles attempted to keep the dialogue open in a spirit of mutual respect. ${ }^{34}$

Hay singles out poor research in nursing, male leadership, and incomprehensible management style for particular criticism. ${ }^{2}$ Perhaps the medical profession should put its own house in order before lecturing others. The stereotype of a domineering (usually male) consultant encouraging his registrar 